\title{
UWB Electric and Magnetic Monopole Antennas
}

\author{
Xiaodong Chen, Member, IEEE, Jianxin Liang, Student Member, IEEE, Pengcheng Li, and Choo C. \\ Chiau, Student Member, IEEE
}

\begin{abstract}
This paper summarizes our recent advances in antenna designs for ultra wideband (UWB) applications. Two types of monopoles are studied and developed in our research group. The first type belongs to the electric monopole with a circular disc fed by three different feeding structures. The second type is the magnetic monopole with an elliptical slot. The performances of these two types of antennas are evaluated in both frequency and time domains. The important design parameters for achieving optimal operations are also analyzed. It is shown that both electric and magnetic monopoles can provide ultra wide bandwidth with nearly omni-directional radiation patterns over the entire frequency band. In addition, the impulse responses of the selected antennas are shown to correspond well to the frequency domain characteristics.
\end{abstract}

Index Terms - Ultra-wide-band (UWB), electric monopole, magnetic monopole, circular disc monopole, printed antenna, slot antenna, coplanar waveguide (CPW).

\section{INTRODUCTION}

U LTRA wideband (UWB) radio technology has been used in the areas of radar, sensing and military communications during the past 20 years. A substantial surge has occurred since February 2002, when the Federal Communications Commission (FCC) of America issued a ruling that UWB could be used for data communications as well as for radar and safety applications [1], [2]. Since then, UWB radio technology has been rapidly advancing as a promising wireless communications technology and attracting considerable research interest around the world.

A UWB system transmits short pulses rather than using a narrowband frequency carrier. Normally, the pulses have very short durations, typically a few nanoseconds, leading to an ultra-wideband spectrum. FCC also allocated a frequency band of $7.5 \mathrm{GHz}$ (from $3.1 \mathrm{GHz}$ to $10.6 \mathrm{GHz}$ ) to UWB applications, by far the largest allocation of bandwidth to any commercial terrestrial system. However, such a huge frequency spectrum

Manuscript received March 1, 2005.

Jianxin Liang, Choo C. Chiau and Xiaodong Chen are with the Department of Electronic Engineering, Queen Mary, University of London, London E1 4NS, UK (Phone: +44 20 78823620, Fax: +44 20 78827997, Email: jianxin.liang(e.elec.qmul.ac.uk).

Pengcheng Li is with Electronic Engineering College, Beijing University of Aeronautics and Astronautics, China. He is also a visiting scholar in Department of Electronic Engineering, Queen Mary, University of London. also provides challenges to antenna designers.

A suitable UWB antenna should have an impedance bandwidth $(-10 \mathrm{~dB})$ larger than the FCC defined frequency band. At the same time, an omni-directional radiation pattern over the entire frequency band is also desirable especially for high data-rate indoor wireless communication systems. Besides, a good time domain performance, i.e. a good impulse response with minimal distortion, is also a primary requirement for the UWB antenna [3] because the signal pulse is the carrier of useful information.

There are a range of classical broadband antennas that are under consideration for use in UWB systems. A straight wire monopole features a simple structure, but its bandwidth is only around $10 \%$. A vivaldi antenna is a directional antenna and hence unsuitable for indoor systems and portable devices. A TEM horn has a big size which limits its application. Log periodic and spiral antennas tend to be dispersive and suffer severe ringing effect. The printed versions of biconical antennas, such as bow-tie-like and the disc dipole [4], [5], need a balanced feed which leads to further complications to the RF circuit. There is a growing demand for small and low cost UWB antennas. Therefore, significant research efforts have been put into the monopole type of UWB antennas by research groups worldwide, including that in our research group [6]-[10].

This paper summarizes our work on two types of UWB monopole antennas, i.e. electric circular disc and magnetic elliptical slot monopoles [6] - [10]. The performances of these two types of antennas are analyzed both numerically and experimentally. All of the simulations are performed by using CST Microwave Studio ${ }^{\mathrm{TM}}$ package which utilizes the Finite Integration Technique for electromagnetic computation [11].

The rest of the paper is structured as the following. Section II presents the electric type of monopole antennas. Section III describes the magnetic type of monopole antennas. Section IV touches on the time domain characteristics of the selected UWB monopoles. A brief conclusion is given in Section V.

\section{ELECTRIC MONOPOLE ANTENNAS}

Several broadband monopole configurations, such as circular, square, elliptical, pentagonal and hexagonal, have been proposed for UWB applications recently [12], [13]. Compared with other configurations, several research groups, including our group, have chosen a circular disc monopole as 
one of the favorite choices for a wider frequency bandwidth. The configuration of the circular disc monopoles has also evolved from a vertical disc to a printed disc on a PCB (Printed Circuit Board).

\section{A. Performances of circular disc monopoles}

The vertical disc monopole originates from the conventional straight wire monopole and is realized by replacing the wire element with a copper disc, as shown in Fig. 1. This antenna has the attractive features of ultra wide bandwidth, omni-directional radiation patterns, simple structure and ease of fabrication. However, it is non-planar structure because the ground plane is perpendicular to the disc. Although the ground plane can be narrowed substantially [6], it is still not suitable for integration with a printed circuit board.

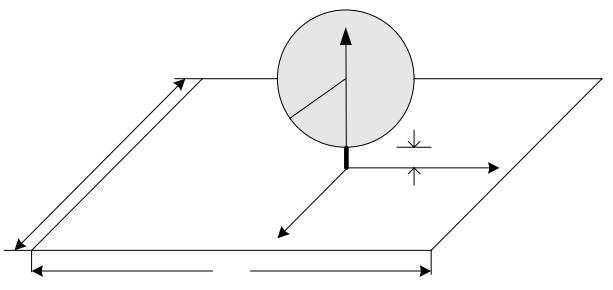

Fig. 1. Geometry of vertical disc monopole

To come up a planar version of UWB disc monopole, a printed feeding structure is required. There are two choices; one is microstrip line and the other CPW feeding structure. These two planar versions of UWB disc monopoles are illustrated in Fig. 2 (a) and Fig. 2 (b), respectively.

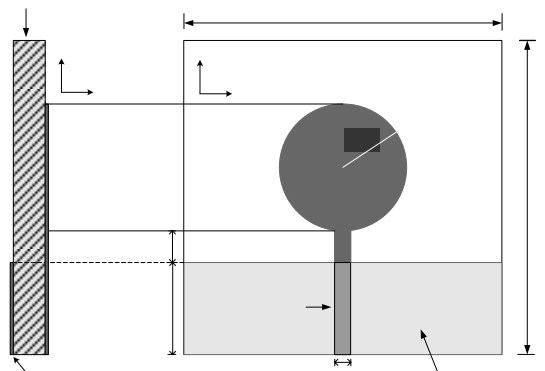

(a) Microstrip line fed disc monopole

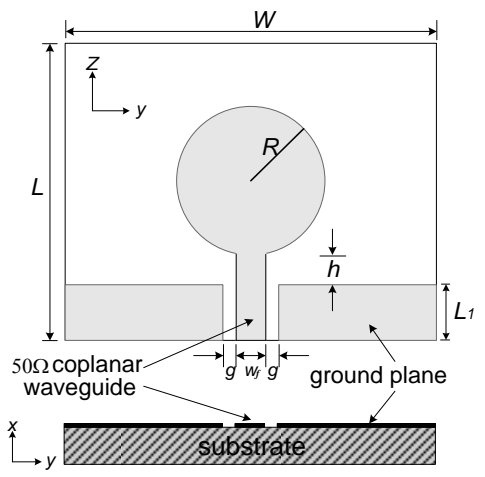

(b) CPW fed disc monopole

Fig. 2. Geometry of printed disc monopoles
The measured return loss curves for the three disc monopoles with their respective optimal designs (vertical disc monopole: $R=12.5 \mathrm{~mm}, h=0.7 \mathrm{~mm}, W=100 \mathrm{~mm}$ and $L=10 \mathrm{~mm}$; microstrip line fed disc: $R=10 \mathrm{~mm}, h=0.3 \mathrm{~mm}, W=42 \mathrm{~mm}$ and $L=50 \mathrm{~mm}$; CPW fed disc: $R=12.5 \mathrm{~mm}, h=0.3 \mathrm{~mm}, W=47 \mathrm{~mm}$ and $L=50 \mathrm{~mm}$ ) are plotted in Fig. 3.

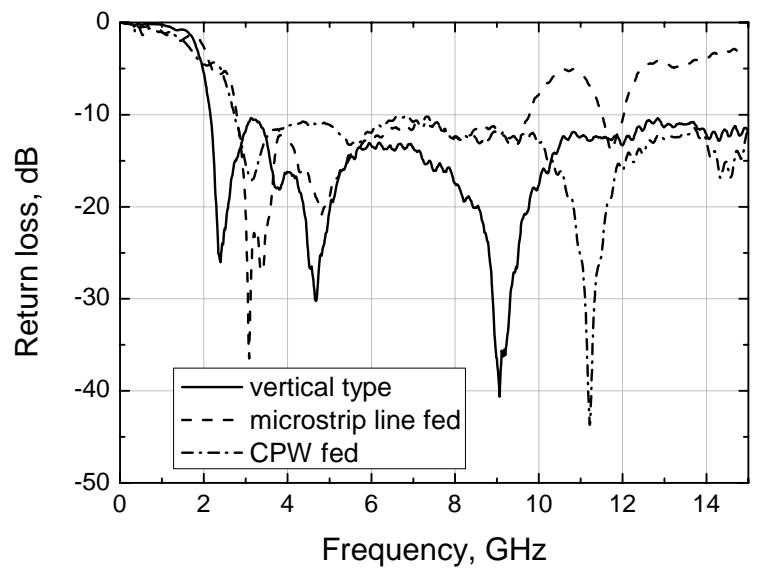

Fig. 3. Measured return loss curves of disc monopole antennas

It is noticed in Fig. 3 that the $-10 \mathrm{~dB}$ bandwidth of vertical disc monopole ranges from $2.16 \mathrm{GHz}$ to $>15 \mathrm{GHz}$, and that of $\mathrm{CPW}$ fed disc monopole from 2.73 to $>15 \mathrm{GHz}$. Both of them can operate across the whole FCC defined UWB frequency band. The bandwidth of microstrip line fed disc monopole spans from $2.78 \mathrm{GHz}$ to $9.78 \mathrm{GHz}$, only slightly narrower than the FCC defined UWB band.

\section{B. Characteristics of circular disc monopoles}

For disc monopole antennas, the ground plane serves as an impedance matching circuit, and it tunes the input impedance by changing the feed gap $h$. So the operating bandwidth of the monopole is very sensitive to the variation of $h$.

Another two important design parameters that affect the antenna performance include the width of the ground plane $W$ and the dimension of the disc. The effects of these two parameters can be well explained by investigating the current distributions of the antenna.

Simulations have shown that disc monopoles with different feeding structures have similar current distributions. Fig. 4 presents the simulated current distributions of CPW fed disc monopole.

As shown in Fig. 4, the current is mainly distributed along the edge of the disc for different frequencies. This demonstrates a number of characteristics of the disc monopoles.

Firstly, the resonant frequency is associated with the dimension of the disc. The diameter of the disc corresponds to one quarter wavelength at the first resonance and hence determines the lower edge of the operating bandwidth.

Secondly, the disc monopole is capable of supporting multiple resonance modes, the higher order modes $\left(f_{2}, f_{3} \ldots f_{n}\right)$ being the harmonics of the fundamental mode of the disc. So the wavelengths of the higher order modes satisfy: 
African Journal of Information and Communication Technology, Vol. 2, No. 1, March 2006

$$
2 R=n \lambda_{n} / 4=\lambda_{1} / 4 \quad \text { (1) }
$$

where $n$ is the mode number. In fact, Fig. 4 (a) shows the current pattern near the first resonance at $3 \mathrm{GHz}$. The current pattern near the second resonance at $5.6 \mathrm{GHz}$ is given in Fig. 4(b), indicating approximately a second order harmonic. Fig. $4(c)$ illustrates a more complicated current pattern at $8.8 \mathrm{GHz}$, corresponding to the third order harmonic. The overlapping of these higher order modes leads to the UWB characteristic, as shown in Fig. 5.
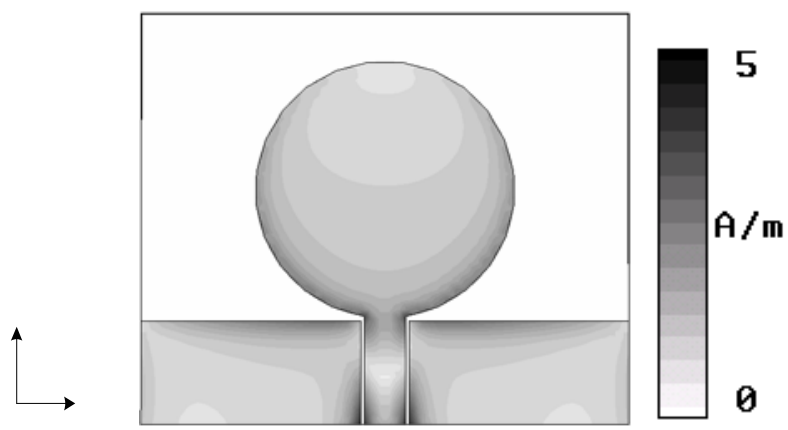

(a) At $3 \mathrm{GHz}$

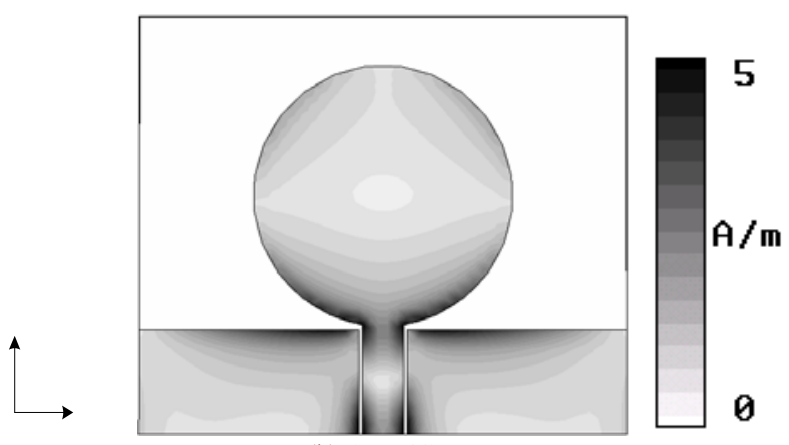

(b) At $5.6 \mathrm{GHz}$

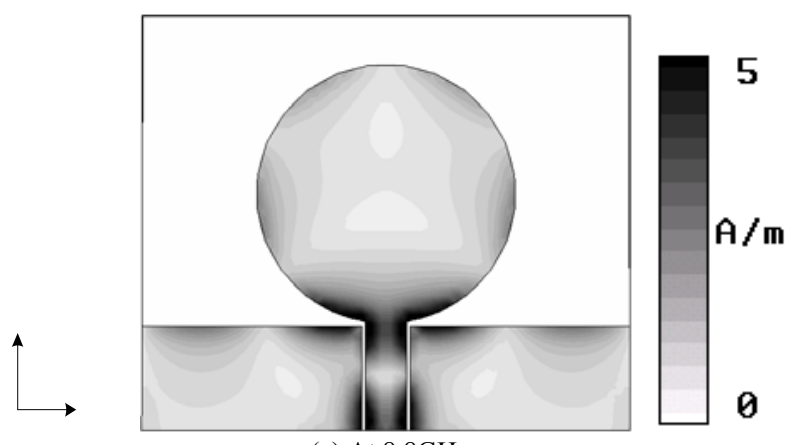

(c) At $8.8 \mathrm{GHz}$

Fig. 4. Simulated current distributions of CPW fed disc monopole

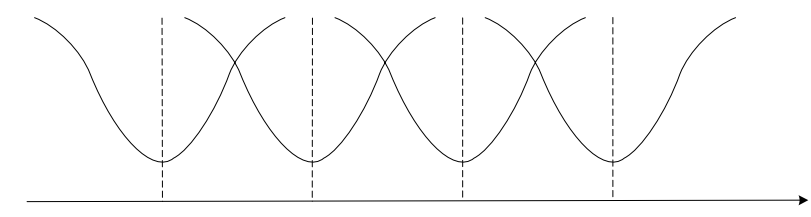

Fig. 5. Overlapping of the multiple resonance modes

Thirdly, cutting the central part of the disc to form a circular ring monopole will not lead to any sacrifice of the bandwidth or serious distortion of the radiation patters [14].

It is also observed in Fig. 4 that, on the ground plane, the current is mainly distributed on the upper edge along the $y$-direction. This indicates that the antenna performance is mainly dependent on the width of the ground plane $W$. So the length of the ground plane $L$ can be much narrower than the width $W$ whilst retaining the UWB characteristic. This is very encouraging for the miniaturization of the antenna.

\section{Radiation patterns of circular disc monopoles}

It has been demonstrated numerically and experimentally that all of the three disc monopoles can exhibit similar radiation properties.

Fig. 6 shows the radiation patterns of microstrip line fed disc monopole. It is noticed that the $E$-plane pattern is like a traditional monopole at $3 \mathrm{GHz}$. With the increase of frequency, it starts to form notches and get more directional at around \pm 30 degrees from the $z$-direction.

The $H$-plane pattern is omni-directional at lower frequency $(3 \mathrm{GHz})$ and is near omni-directional at higher frequencies $(9 \mathrm{GHz})$, where the gain reduces $8 \mathrm{~dB}$ in the $x$-direction at $9 \mathrm{GHz}$. So the disc monopole is generally omni-directional over the entire bandwidth.

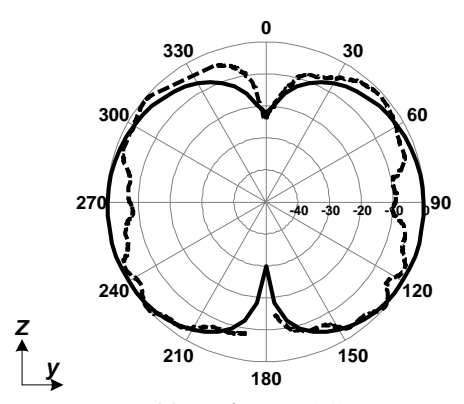

(a) $E$-plane at $3 \mathrm{GHz}$

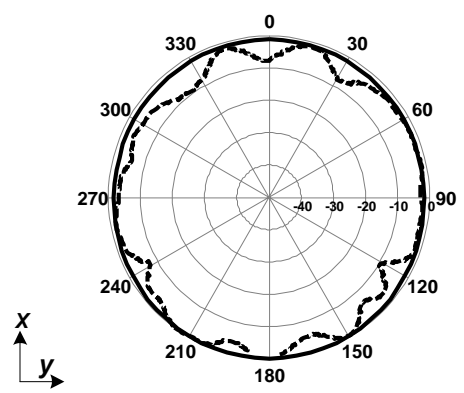

(c) $H$-plane at $3 \mathrm{GHz}$

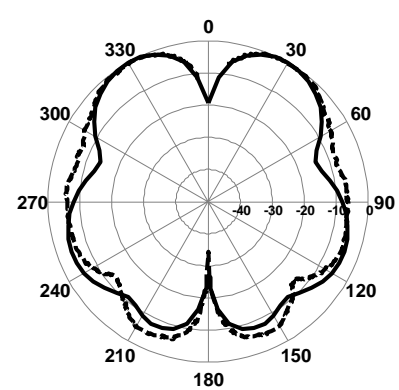

(b) $E$-plane at $9 \mathrm{GHz}$

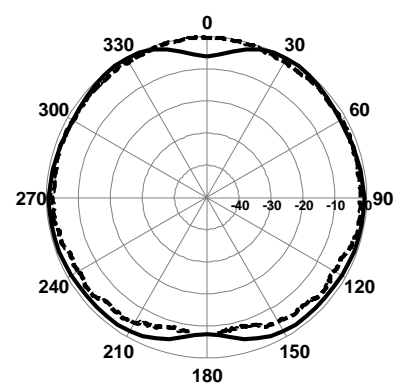

(d) $H$-plane at $9 \mathrm{GHz}$
Fig. 6. Simulated (solid line) and measured (dotted line) radiation patterns of microstrip line fed disc monopole

\section{MAGNETIC MONOPOLE ANTENNAS}

In contrast to electric monopole antennas, wherein the copper disc serves as the radiator, magnetic monopoles use slot as the radiating element. In this section, elliptical slot antennas with two different feeding structures, i.e. microstrip line and $\mathrm{CPW}$, are investigated. 


\section{A. Performances of elliptical slot antennas}

The geometries of two printed elliptical slot antennas are illustrated in Fig. 7. For both of the antennas, the elliptical slot is etched from the ground plane. A U-shaped tuning stub is used to improve the coupling between the feed line and the slot. The tuning stub is all positioned within the elliptical slot region and symmetrically with respect to the short axis of the elliptical slot. Besides, an additional bandwidth enhancement can be achieved by tapering the feed line with a slant angle $\theta$ for a distance of $H$.

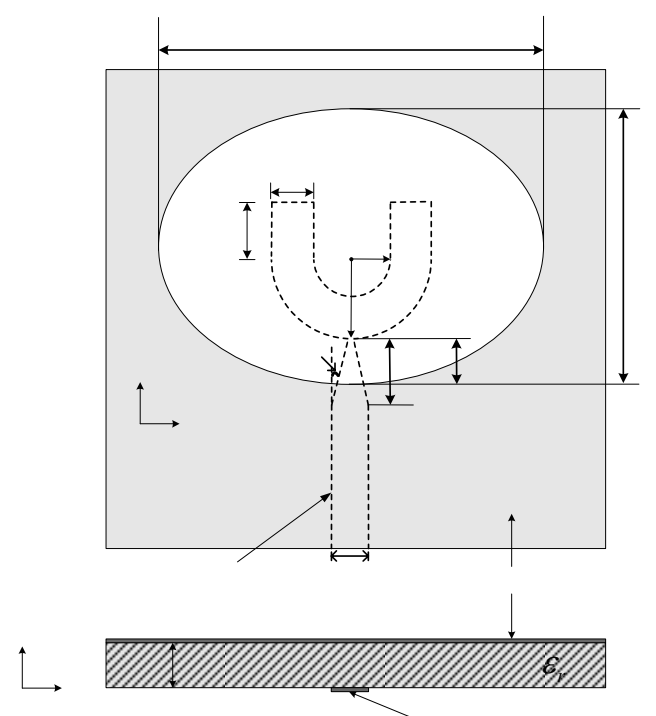

(a) Microstrip line fed elliptical slot antenna

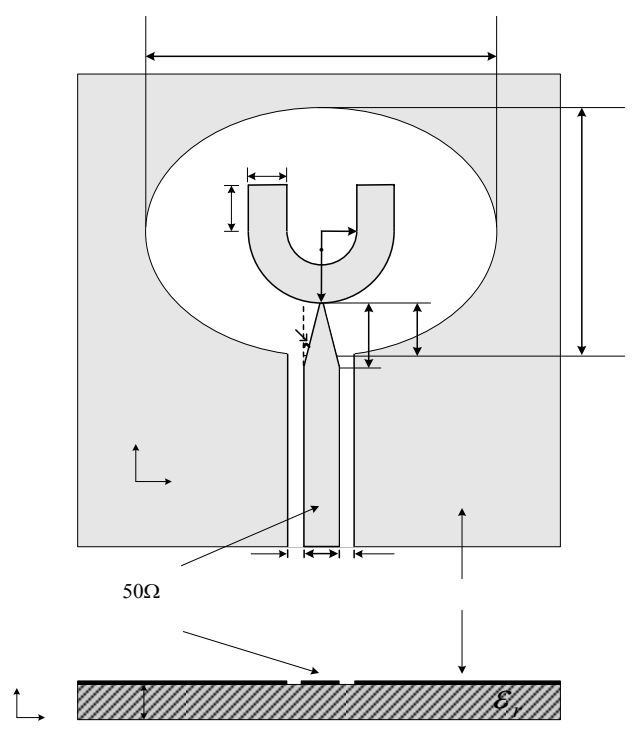

(b) CPW fed elliptical slot antenna

Fig. 7. Geometry of printed elliptical slot antennas

Measurements have shown that the optimal designs of both the two slot antennas (microstrip line fed slot antenna with $\theta=15, H=3 \mathrm{~mm}, S=0.6 \mathrm{~mm}, A=16 \mathrm{~mm}$ and $B=11.5 \mathrm{~mm}$; CPW fed slot antenna with $\theta=15, H=2.5 \mathrm{~mm}, S=0.4 \mathrm{~mm}, A=14.5 \mathrm{~mm}$ and $B=10 \mathrm{~mm}$ ) can achieve ultra wide bandwidths. As shown in Fig.
8 , the measured $-10 \mathrm{~dB}$ bandwidth of microstrip line fed elliptical slot antenna is from $2.6 \mathrm{GHz}$ to $10.22 \mathrm{GHz}$, and that of the CPW fed one from $3.1 \mathrm{GHz}$ to $10.55 \mathrm{GHz}$.

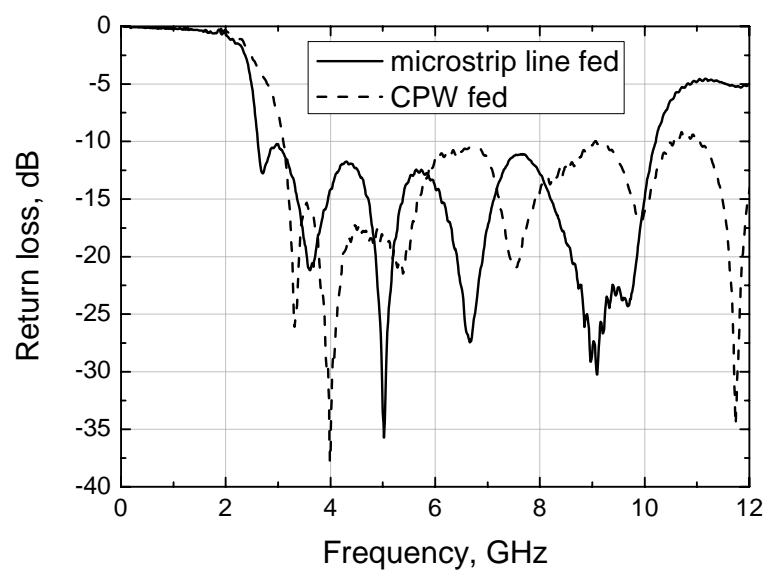

Fig. 8. Measured return loss curves of elliptical slot antennas

\section{B. Design parameters of elliptical slot antennas}

The simulations reveal that the ultra wide bandwidth of the slot antenna results from the multiple resonances introduced by the combination of the elliptical slot and U-shaped tuning stub. Consequently, the slant angle $\theta$, the tapered length $H$, and the distance $S$ between the stub and the bottom of slot are the most important parameters which affect the antenna performance. These parameters should be optimized for maximum bandwidth.

Moreover, the lower edge of $-10 \mathrm{~dB}$ bandwidth is directly associated to the dimension of the slot $(A$ and $B)$. An empirical equation is introduced to describe the relationship between the lower frequency edge $f_{l}$ and the slot dimension, as given in (2).

$$
f_{l}=\frac{30 \times 0.32}{2 A+0.25 B}
$$

where $A, B$ in $\mathrm{cm}$, and $f_{l}$ in $\mathrm{GHz}$.

The comparison between the calculated $f_{l}$ and the measured one for different printed slot antennas are tabulated in Table 1. It shows a good agreement between the calculated and measured $f_{l}$.

Table. 1. The calculated and measured lower edge of bandw

\begin{tabular}{|c|c|c|c|c|}
\hline $\begin{array}{c}\text { Elliptical } \\
\text { slot antenna }\end{array}$ & $\begin{array}{c}A \\
(\mathrm{~mm})\end{array}$ & $\begin{array}{c}B \\
(\mathrm{~mm})\end{array}$ & $\begin{array}{c}\text { Measured } \\
f_{l}(\mathrm{GHz})\end{array}$ & $\begin{array}{c}\text { Calculated } \\
f_{l}(\mathrm{GHz})\end{array}$ \\
\hline $\begin{array}{c}\text { Microstrip } \\
\text { line fed }\end{array}$ & 16 & 11.5 & 2.6 & 2.74 \\
\hline $\begin{array}{c}\text { Microstrip } \\
\text { line fed }\end{array}$ & 13.3 & 13.3 & 3.46 & 3.21 \\
\hline CPW fed & 14.5 & 10 & 3.1 & 3.17 \\
\hline CPW fed & 13.3 & 13.3 & 3.75 & 3.21 \\
\hline
\end{tabular}




\section{Radiation patterns of elliptical slot antennas}

The radiation patterns of CPW fed elliptical slot antenna with the optimal design are illustrated in Fig. 9. It is noticed that the radiation properties of elliptical slot antenna are similar to those of disc monopole, i.e. the $E$-plane pattern is monopole-like and the $H$-plane pattern is nearly omni-directional over the entire bandwidth.

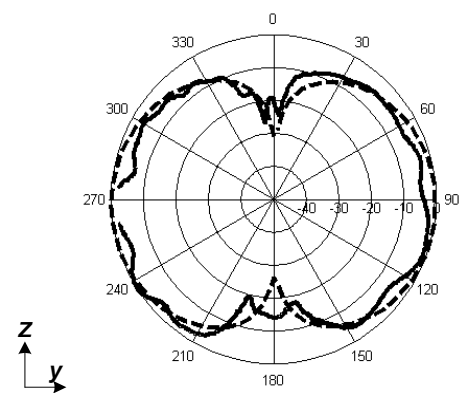

(a) $E$-plane at $3.1 \mathrm{GHz}$

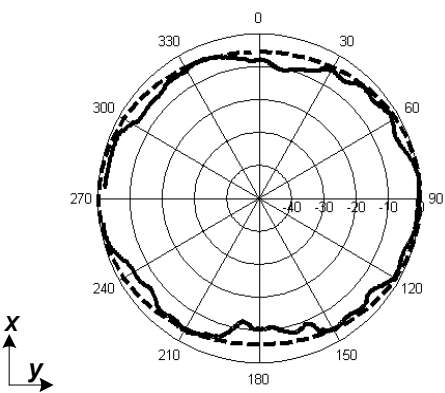

(c) $H$-plane at $3 \mathrm{GHz}$

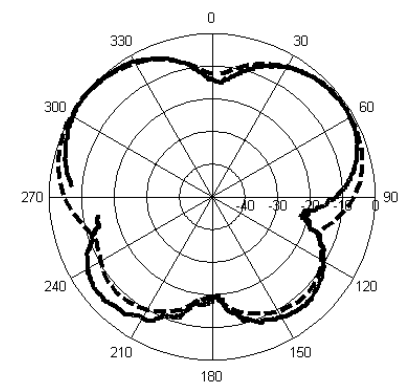

(b) $E$-plane at $10 \mathrm{GHz}$

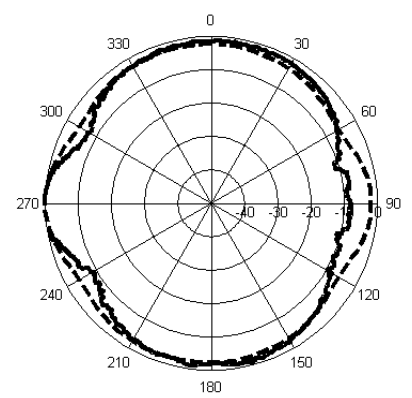

(d) $H$-plane at $10 \mathrm{GHz}$
Fig. 9. Simulated (solid line) and measured (dotted line) radiation patterns of CPW fed elliptical slot antenna

\section{ANTENNA PERFORMANCE IN TIME DOMAIN}

The time domain characteristics of vertical type and microstrip line fed disc monopoles are examined numerically. In the modelling, the antennas system comprises of two identical disc monopoles. The transmitter and receiver are positioned face to face with a distance of $1.2 \mathrm{~m}$. A first-order Rayleigh pulse, as presented in (3), is used as the source signal to drive the transmitter.

$$
f(t)=\frac{-2(t-1)}{a^{2}} \exp \left(-\left(\frac{(t-1)}{a}\right)^{2}\right)
$$

In this study, the pulse parameter $a$ is fixed at 45 ps such that the pulse spectrum peaks at around $5 \mathrm{GHz}$, as given in Fig. 10. It is also noticed in Fig. 10 (b) that the pulse spectrum has a -10 $\mathrm{dB}$ bandwidth of $13.5 \mathrm{GHz}$, from $0.3 \mathrm{GHz}$ to $13.8 \mathrm{GHz}$. The lower edge of the pulse bandwidth is smaller than those of the two monopoles, while its upper edge is higher than microstrip line fed disc, but lower than the vertical one, as shown in Fig. 3.

The impulse response of vertical disc monopole is plotted in Fig. 11. The received signal waveform generally follows the source pulse, but has a slight ringing effect. This is mainly due to the bandwidth mismatch between the source pulse and the antenna, as shown in Fig. 10 (b). Some low frequency components of the pulse can not be efficiently transmitted by the disc monopole.

The time domain performance of microstrip line fed disc monopole is inferior to vertical disc. Fig. 12 (a) illustrates that the received signal has more distortions. This is because of the narrower operating bandwidth of this type monopole. Compared with vertical disc, microstrip line fed disc monopole has filtered more pulse components, as shown in Fig. 10 (b). The results indicate that the impulse responses of the antennas correspond well to the frequency domain performances.

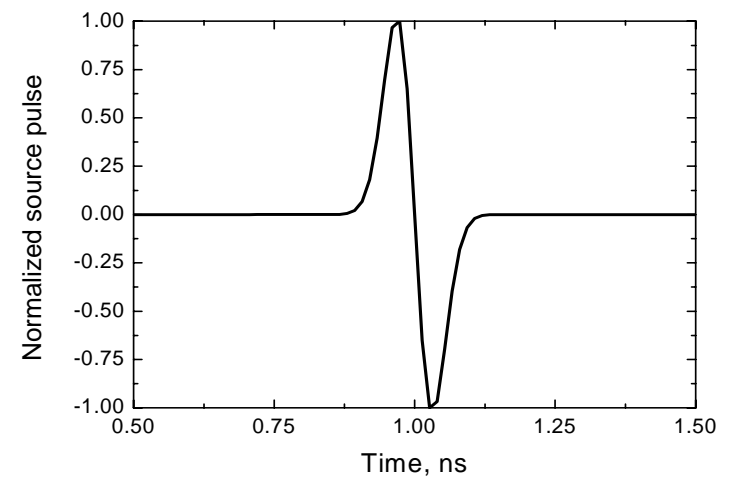

(a) Source pulse waveform

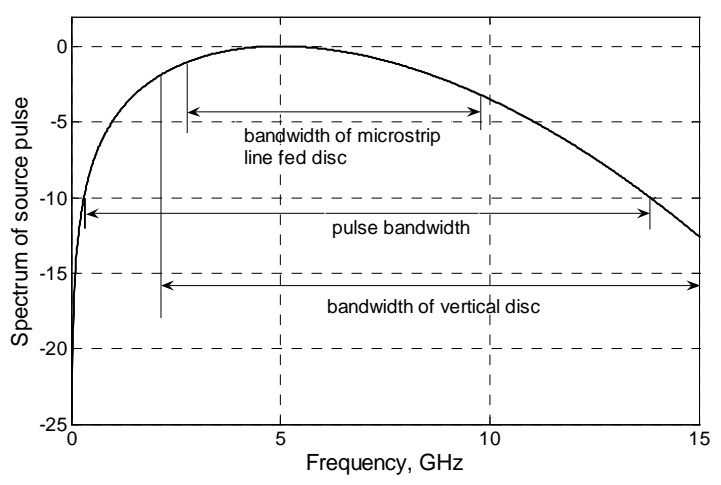

(b) Pulse spectrum

Fig. 10. First-order Rayleigh pulse

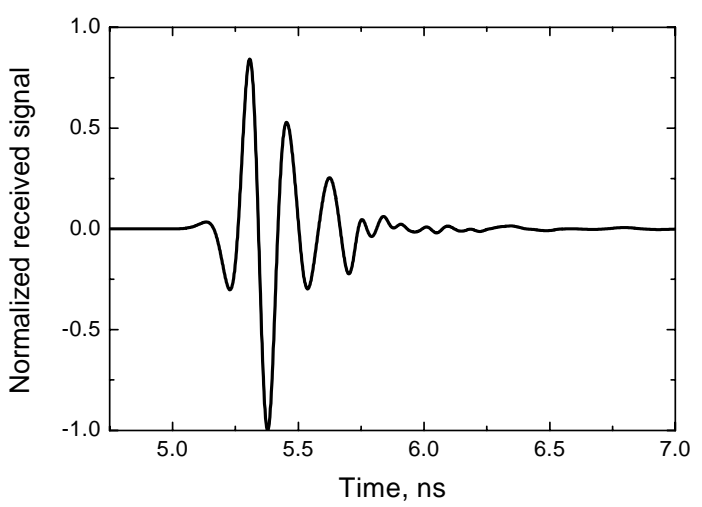

(a) Received signal 
African Journal of Information and Communication Technology, Vol. 2, No. 1, March 2006

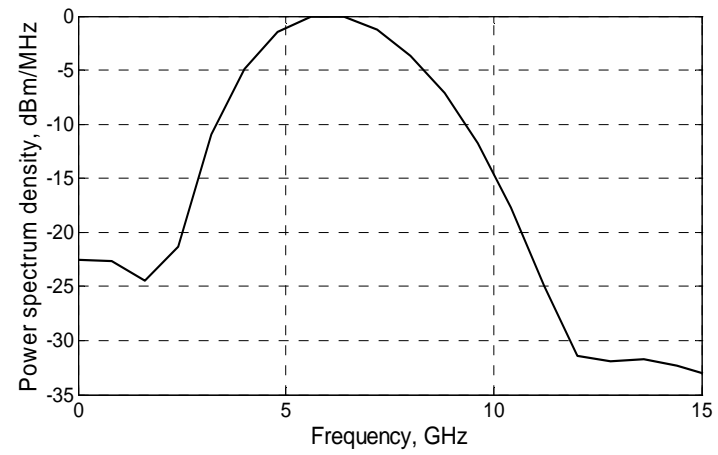

(b) Received power spectrum density

Fig. 11. Impulse response of vertical disc monopole

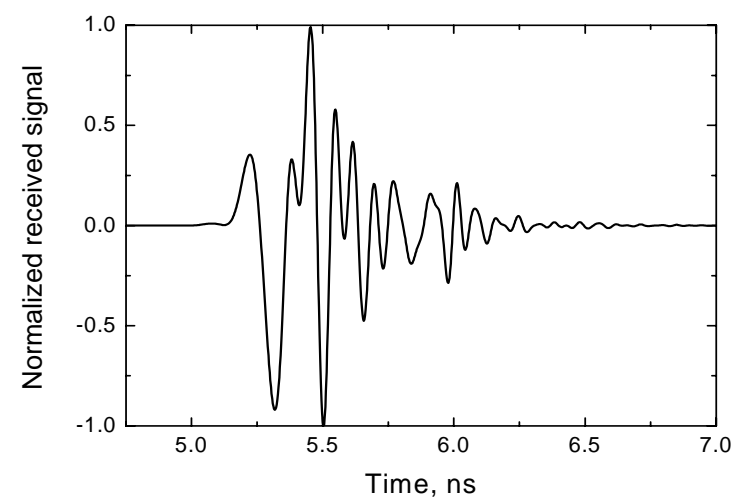

(a) Received signal

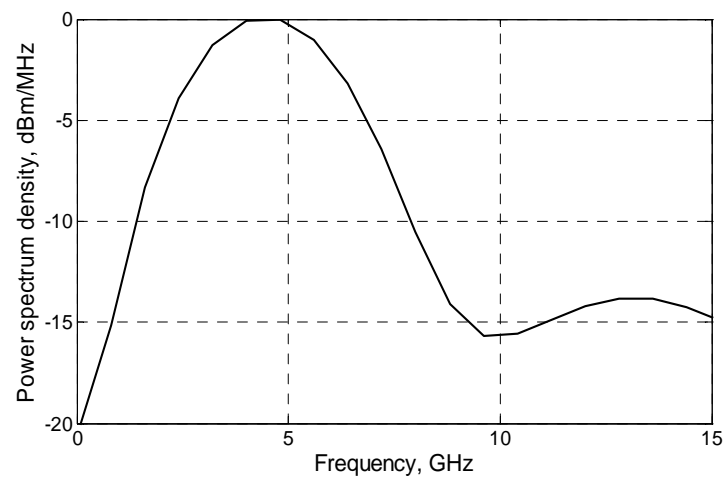

(b) Received power spectrum density

Fig. 12. Impulse response of Microstrip line fed disc monopole

\section{CONCLUSION}

This paper is a brief summary of our recent research work on UWB antennas. Two types of antennas, i.e. circular disc monopoles (electric monopoles) and elliptical slot antennas (magnetic monopoles) are investigated with an emphasis on the understandings of antenna operations. Studies have demonstrated that both of the two types of antennas can exhibit UWB characteristics with nearly omni-directional radiation patterns over the entire bandwidths. It is also shown that antenna characteristics in time domain correspond well to those in frequency domain. Moreover, planar versions of UWB antennas, fed by microstrip line or coplanar waveguide, feature low profile, small size and suitability for integration with printed circuit board, which make them promising for future
UWB applications.

\section{ACKNOWLEDGMENT}

The authors would like to thank Mr. John Dupuy of the Department of Electronic Engineering, QMUL for his help in the fabrication and measurement of the antenna. The authors would like to acknowledge Computer Simulation Technology (CST), Germany, for the complimentary license of the Microwave Studio ${ }^{\text {TM }}$ package.

\section{REFERENCES}

[1] I. Oppermann, M. Hämäläinen and J, Iinatti, "UWB Theory and Applications", (C) 2004, John Wiley \& Sons, Ltd.

[2] FCC Report and Order for Part 15 acceptance of Ultra Wideband (UWB) systems from $3.1-10.6 \mathrm{GHz}$, February, 2002, FCC website.

[3] H. G. Schantz, 'Ultra Wideband Technology Gains a Boost from New Antennas', Antenna Systems and Technology, vol. 4, no. 1, January/February 2001.

[4] Les Smith, Tim Strarkie and Jack Lang, "Novel UWB Antennas-Theory and Simulation", 2004 International Workshop on Ultra Wideband Systems Joint with Conference on Ultra Wideband Systems and Technologies, Kyoto, Japan, May 18-21, 2004.

[5] John D. Kraus and Ronald J. Marhefka, "Antennas for All Applications", Third Edition, McGraw-Hill Higher Education, 2002.

[6] Liang, C.C.Chiau, X. Chen, and C.G.Parini, "Analysis and design of UWB disc monopole antennas", The IEE Seminar on Ultra Wideband Communications Technologies and System Design, pp. 103-106, 8 July 2004, at Queen Mary, University of London.

[7] J. Liang, C.C.Chiau, X. Chen, and C.G.Parini, "Printed circular disc monopole antenna for ultra wideband applications", Electronics Letters, Vol. 40, no. 20, pp. 1246-1248, 30th September 2004.

[8] J. Liang, L. Guo, C. Chiau and X. Chen, 'CPW-Fed Circular Disc Monopole Antenna for UWB Applications', IEEE International Workshop on Antenna Technologies (iWAT 2005), Singapore, 7-9 March 2005 (acceptted).

[9] P. Li, J. Liang and X. Chen, "Ultra-wideband elliptical slot antenna fed by tapered micro-strip line with U-shaped tuning stub", IEE Electronic Letters, 2005, submitted for publication.

[10] P. Li, J. Liang and X. Chen, "Coplanar Waveguide Fed Elliptical Slot Antenna", IEEE Microwave and Wireless Components Letters, 2005, submitted for publication.

[11] CST-Microwave Studio, User's Manual, 4, 2002.

[12] M.J.Ammann, Zhi Ning Chen, "Wideband Monopole Antennas for Multi-Band Wireless Systems", IEEE Antennas and Propagation Magazine, vol. 45, no. 2, pp. 146-150, April 2003.

[13] Narayan Prasad Agrawall, Girish Kumar, and K. P. Ray, "Wide-Band Planar Monopole Antennas", IEEE Transactions on Antennas and Propagation, vol. 46, no. 2, pp. 294-295, February 1998.

[14] J. Liang, C Chiau and X. Chen, "Printed circular ring monopole antennas", Microwave and Optical Technology Letters, accepted and to be published in June 2005 .

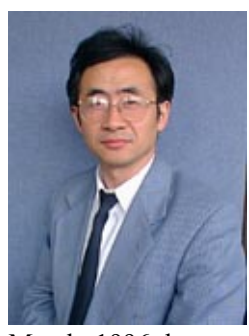

Xiaodong Chen (M'96) received the degree of B.Sc. in Electronic Engineering from the University of Zhejiang, Hangzhou, China in 1983, and the degree of $\mathrm{Ph} . \mathrm{D}$. in microwave electronics from the University of Electronic Science and Technology of China, Chengdu in 1988. In September 1988 he joined the Department of Electronic Engineering at King's College, University of London, as a Postdoctoral Visiting Fellow. In September 1990 he was employed by the King's College London as a Research Associate. In March 1996 he was appointed to an EEV Lectureship at King's College London. In September 1999 he joined the Department of Electronic Engineering at Queen Mary and Westfield College, University of London as a College Lecturer. In October 2003, he was promoted to a Readership at the same institution. 
His interests are in microwave devices and antennas, bio-electromagnetic and nonlinear dynamics and chaos. He has authored and co-authored over 130 publications (book chapters, journal papers and refereed conference presentations). He has involved in the organisation of many international conferences; he has served as Chairman of Institute of Electrical Engineers (IEE) International Workshop on Ultra Wide Band Technologies and Systems (2004), co-chairman of the Institute of Physics (IoP) / IEE International Workshop on RF Interaction with Humans (2003), Executive Chairman of 'The International Conference on Telecommunications (ICT), 2002'. He is currently a member of UK EPSRC Review College and Technical Panel of IEE Antennas and Propagation Professional Network.

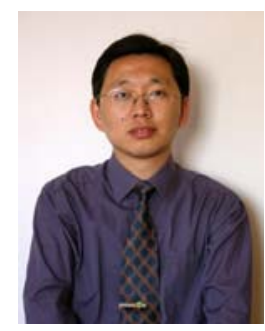

Jianxin Liang (S'04) received the B.Sc. and the M. Sc. degrees from Nankai University, China in 1995 and 1998, respectively. Currently, he is studying towards the Ph.D. in the Communications Research Group, Department of Electronic Engineering, Queen Mary, University of London, UK. His current research interests focus on UWB antenna design and analysis.

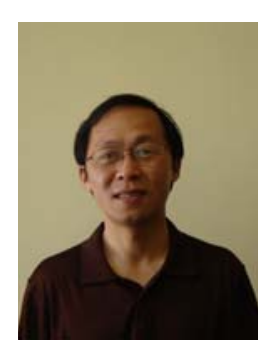

Pengcheng $\mathbf{L i}$ received the B.Sc. degree from Xiangtan University, China in 1985, and the M. Sc. degree from Beijing Research Institute of Telemetry Technology, China in 1991. Currently, he is studying towards the Ph.D. in Electronic Engineering College, Beijing University of Aeronautics and Astronautics, China. From September, 2004 to March, 2006, he has been awarded financial support under the Chinese Scholarship Fund to pursue research in the Communications Research Group, Department of Electronic Engineering, Queen Mary, University of London, UK as an academic visitor. His current research interests focus on UWB antenna design and analysis, and microwave circuit.

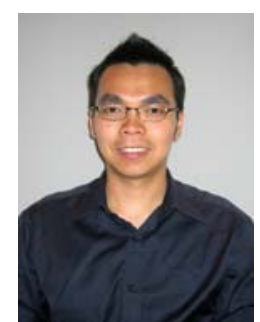

Choo C. Chiau (S'04) received the B.Sc degree in Microelectronics from Tunku Abdul Rahman College (TARC), Malaysia in 2000 and the M.Sc degree in Mobile and Satellite Communications from University of Surrey, U.K., in 2001. Currently, he is studying toward the $\mathrm{Ph} . \mathrm{D}$ degree in the Communications Research Group, Department of Electronic Engineering, Queen Mary, University of London, U.K. His current research interests are MIMO system, Bio-Electromagnetics, applications of Electromagnetic Band-Gap (EBG), diversity antenna, dielectric antenna and UWB antenna design. 